\title{
The research on gender discrimination in news media language
}

\author{
Hujian Zhou \\ The Hong Kong Institute of Education \\ Hong Kong,China
}

\begin{abstract}
In most of the male-dominated society, English and Chinese language reflects social discrimination against women abound, so research on gender differences and gender discrimination language in question has been the focus of concern of sociolinguistics one. Taking the perspective of the news media language, we explore the media coverage of gender discrimination and its causes.
\end{abstract}

News media, language and gender discrimination

Keywords-component; formatting; style; styling; insert

\section{ENGLISH-CHINESE PHRASEBOOK SEXISM EXISTS}

Women constitute the corresponding noun after the men noun suffix -ess/-ette, for example: waiter / waitress. The higher social status occupations such as doctor, lawyer, etc., have no corresponding female nouns. When we refer to these occupations of women, we use woman / female / lady / girl as attribute. And ironically, ideas, words containing sex, marriage and nursing women are usually used for word stemming, derived from the word man, for example: prostitute is the root, derived male prostitute, bridegroom derived from the bride. Some words contain both male and masculine including the feminine, such as "man" can refer to males, men, and women, including; many men, many minds. In the phrase structure, men word usually located in the front, such as the husband and wife, king and queen. There are a lot of English words insulting to women, such as slut, gossip, spinster. Some refer to men and women have a completely different connotation. Men usually contain the power of the word, meaning powers, while women contain the low status, such as the corresponding word master and mistress, master means master, and mistress in addition to refer to female owner, you can also refer to a mistress. Contains the same word referring to men, it means compliment, referring to women, Shique derogatory, for example: He is a professional: he is a member of a respected profession. She is a professional: she is a member of the oldest profession (prostitute). There is also phrase structure praise, derogatory points, such as the phrase man on (in) the street ordinary man, and woman (lady) on (of) the street, referring to a prostitute. Some women insulting words are used to form phrases, such as: black widow spider (tarantula).

\section{THE CAUSES OF GENDER DISCRIMINATION}

Gender discrimination has existed for a long time, which is also reflected in the language. It is traced, mainly in the following aspects:

\section{A. Cultural roots}

In both English and Chinese, there is Goddess and God making man's legend. And surprisingly there are the first two legendary man then we have a woman and a woman in the Bible is part of the man, which seems to determine that the woman is man's accessories, and is subordinate to men in the community while men are naturally dominating the entire world.

\section{B. Historical Roots}

Gender discrimination in human society has existed for a long time. Before primitive society and caste system of private ownership, it appears to maternal ancestor of humans to maintain tribal. Women bear the gathering, planting and other major production activities, and thus they have dominant position at the time. But with the development of productive forces, men gradually play a more important role in production activities. It has gradually replaced the female dominance. Women began to become a subsidiary of men, and were in fact living in slave status.

\section{Physiological roots}

Due to differences in the physical structure of men than women, men seem to be sturdier and seem to be more socially responsible. They assume construction, management and even ruled the whole society, including women. Thus it becomes a strong male dominated society as a whole. This kind of thinking caused by the differences in the physical structure of thinking gradually integrate into society, the formation of a culture of gender discrimination in the culture is also deeply penetrated into every aspect of people's lives.

\section{THE PHENOMENA OF GENDER DISCRIMINATION IN THE NEWS MEDIA LANGUAGE}

Whether in China or Western countries, the media as "social instrument" has become a consensus. The media is often also in the embodiment of justice axiom itself. Real, objective requires news media practitioners to use language to accurately reflect the current social reality, and it is a matter of concern to the media function. Perhaps 
unconsciously, gender inequality and discrimination do exist in the real media.

\section{A. Male-centered perspective}

It has been a long time since male-centered social forces and the traditional concept are still reflected in the news media reports. The following is the UK's mainstream media Daily Telegraph (Daily Telegraph) and popular welcomed the tabloid The Sun (Sun) reported for the same event. -A man who suffered head injuries when attacked by two men, who broke into his home in Beckenham, Kent, early yesterday, was pinned down on the bed by intruders who took it in turns to rape his wife (Daily Telegraph)-A terrified 19. - Stone husband was forced to lie next to his wife as two men raped her yesterday. (Sun)

These two news reports talks about the same thing: Two burglaries broke into Kent County families. The husband of the head injured, was also forced to lie to his wife watching his wife being raped. Whether it is in a serious newspaper or in gossip tabloids are the victim of men in a prominent position. In two reports, man and husband is the first to be mentioned, as the subject of the sentence; predicate suffered and was forced to use the verb illustrate two men reported how humiliated, hurt the woman. People will ask: Who exactly is more hurt? Wife raped or head injuries, forced to watch his wife humiliated husband. Both the reports did not mention the woman's name or her occupation, but by using "his wife". Obviously, in the subconscious of the news staff, it seems to be a woman who was gang-raped suffered more than her husband, or that his wife raped is painful, but the devastated husband is more painful. These two reports may cause many readers resonate because the outdated concept stereotype is difficult to be changed or eliminated. The news media is a reflection of the objective facts and coverage of an event lack of impartiality, objectivity, or intentionally or unintentionally spread and replicate mission with journalists costarring information and ideas is virtually strengthened rooted in people's minds the idea of gender discrimination .

\section{B. Chastity}

1998 On Tang Shengli (to refuse to escort young women jumping from a building in Sichuan ) reports, the language used by reporters such as: rather die than be escort woman, in order to make money, at the expense of an innocent girl, praise her better dying when life is a disgrace, with blood maintained his innocence, and so on.

- Report entitled "Should withered buds". The narrative of a girl was trafficked to the Gobi Desert in Xinjiang. The girl was abducted in 14, and has children in 15, and then she was rescued. "Xu Xiaolan finally returned home after an absence of more than a year. But a year later, she was not that pure girl. --- Transfer from Beijing Youth Daily. Similarly, women were raped, but authors tend to emphasize woman's human rights are not being violated. It was stressed that if a woman lost precious virginity. Journalists use moral judgments to victims such as noble, pure, innocent. These are the result of people's subconscious stereotypes of gender discrimination, which reflected the feudal concept of chastity in the news. The woman lost her virginity is no longer pure.
Should you feel shame, due to be branded with the scarlet letter? People should understand women were force to do things with violence or other unlawful means, and it should not be a disgrace to women, but shame to the perpetrators. The perpetrators are not pure, the social stigma, either. Female body was hurt, but their reputation and spiritual life should not be hurt. Innocence (or virginity) is a kind of spiritual patriarchal culture oppression of women. This oppression has appeared in the modern media reports. Unfortunately, when young girl was raped, language reporters' use is: "people ruined"; Some reports also stressed virginity inadvertently in female crime, so they lost youth. Lost 773 Lee wax flowers: news media language gender discrimination has lost self-esteem, then write oneself off as hopeless and act recklessly, become criminals, etc. These will undoubtedly strengthen the stereotype of women.

\section{Ornamental value}

Even in the case of the evaluation of a wide range of women, media reports tend to view women as visual senses objects. Ornamental value is still the most important social value of women. Ornamental value in the commercial reports, mass media emphasized that the ornamental value of women. The emergence of gender discrimination in the report, the law is not perfect in this society, money can do whatever they want, but money does not have to live in dignity and rights of the edges. As of this vulnerable group of women, there are no equal employment opportunities without adequate legal protection; more important is the potential lag behind social concepts, and how they can really get rid of the shackles. When women are not seen as a complete individual intelligence, courage, and other quality, they are regarded as the object. Its ornamental (or pretty degree) level determines the value of this women. Elegant and refined country aviation sister, bright red China Southern flight attendants, golf altar Romances: Woods was with a beautiful girlfriend, beautiful female commandos witnessed the hijacking and the author of more than counter-terrorism operations in the online media coverage was a woman. Random search from the title, no one exception, and women became the object viewing. Look at the following headings:

- CPPCC first press conference of beautiful female translator is still in the framework of male-centered, emphasizing the physical and biological characteristics of the image of women (are ornamental), while ignoring the social characteristics of women. An appeal to women for their beauty, the interpreter is not respected. Does the performance of work emphasize on women's beauty? She won the job because of talent, not looks; publishing this photo is also disrespect for women, because women work in two sessions instead of being viewed; publishing this photograph is not respect for the reader, because the expectations are not reported. Imagine the CPPCC title first press conference handsome male interpreter. What would be the effect? Readers simply can not see this headline in the media, nor the men's appearance. Media emphasizing on gender, female appearance, clothing, mannerisms compliment actually reflects the gender discrimination. 


\section{THE METHOD OF OVERCOMING GENDER DISCRIMINATION IN LANGUAGE}

As an aspect of human society for thousands of years of culture, gender discrimination has deeply penetrated into people's thinking and behavior patterns, and foolproof to eliminate gender discrimination is almost impossible, at least for a long period of time. However, in science, technology and society, they have a great wealth of material and spiritual development today. The awakening of female consciousness and gender ideology, allows us must make a change. Therefore, in our daily lives several parties deserve our attention:

\section{A. Shift people's thought}

Language, gender discrimination, discrimination rooted in gender awareness in people's ideology. To change the gender discrimination language, the most important is to root in people thinking the idea of equality and respect for woman's equal rights. The mass media as a product of human civilization, women play a crucial role in the development process. In modern history, the mass media to advocate the emancipation of women, gender equality, promote the progress of human civilization. Although the mass media in promoting gender equality and promote women's development plays an active role in understanding and respect for women has been a lot of progress than in the past, but we can still prejudice against women in the mass media. Although the means of mass communication in today won an unprecedented development, however, improve the dissemination of technology does not necessarily bring the media and cultural progress, on the contrary, we can often find many full of a variety of gender stereotypes in the media, and even prejudices discrimination and cultural information, and more worrying is that it began in a more subtle way to infiltrate our lives.

\section{B. Avoid the use of certain pronouns}

We should try to use neutral words, and avoid the use of personal pronouns such as him. You can use the plural form, instead of the first person or third person, dynamic, etc.; avoid using man / men / mankind refers to a person, and we use the following neutral words: people person humanity humankind human being. Now we become inadequate or completely untenable categorically transition to new research methods, in line with the more advanced stages of scientific understanding way of thinking. This means that with the accumulation of facts and deal with new materials, scientists increasingly believe in the framework of the existing way of thinking impossible for them to make a profound theoretical generalization and reasonable explanation. Therefore, we must decisively abandon previously existing explanations and things, and use the same approach in principle. That is changing the way of thinking of scientists from the root. The emphasis here is that you must destroy the rigid traditions such as the road of scientific development obstacles and resistance. The old tradition of thinking should be reinvented, and then destroy the fundamental old ideas, old things through practice and a new scientific theory and scientific and technical means and converted into a new actual development of a systematic, open, dynamic way of thinking.

\section{Change Science and technology revolution with its special social function also influence and driving the change of thinking mode}

Modern technology revolution gives people a powerful tool for understanding. It is not only in the electron microscope, but also strengthen the telescope observation tools such as a person's sense organs, intelligence organs to have "enhanced the person's thinking organ; technological revolution makes understanding objects undergo significant changes, system theory, information theory and cybernetics by making use of knowledge objects from a simple assessment of complex assessments, namely multi-funded dynamic systems and open systems, dissipative structure theory, coordination theory, catastrophe theory and then study open systems formation, evolution and development, as well as order-disorder into each other, forming a system of thinking and awareness activities to promote the emergence of mathematical, modeling, formal trend.

\section{REFERENCES}

[1] Lilahua. Language news media sexism [J]. Huazhong Agricultural University (Social Science Edition),2004,03:75-78.

[2] Jiang Yanling. English language Sexism and evolution [J]. NINGBO UNIVERSITY (LIBERAL ARTS EDITION),2004,03:48-51.

[3] Zhang Peifang. Gender and English language discrimination and its causes [J]. Luoyang Technology College,2006,05:52-55.

[4] Lizhi. Terence English language sexism discrimination vocabulary from watching Inner [J].Mongolia Agricultural University (Social Science Edition), 2007,05:373-374 +380.

[5] Lin li. From evolution vocabulary of English language sexism [J]. Hotan Teachers College,2008,06:135-136.

[6] Zhuli. Interpretation Sexism in the English Language [J]. Guangxi Vocational and Technical College,2008,01:57-61.

[7] Liu Xiaohong, Liu Fengge. "Bible" of the original template language phenomenon of gender discrimination [J]. Hangzhou University of Electronic Science and Technology (Social Science Edition),2008,02:55-58.

[8] Wang Ning. English language study of gender discrimination [J] Technological information (science and research), 2008,21:237.

[9] Zhang Suyue. From the perspective of social linguistics Sexism in the English Language $[\mathrm{J}]$ analysis of Liaoning Administration College,2008,08:199 -200. 